\title{
Experimental Substantiation for the Effectiveness of Gastrostomy using a Polypropylene Endoprosthesis Based on a Comparative Morphological Assessment of the State of the Hollow Organs of the Gastrointestinal Tract
}

\author{
Sergey N. Shurygin, PhD, ScD ${ }^{1}$; Alexey G. Vaganov²; Archil S. Tsulaya ${ }^{1}$; \\ Dmitriy A. Volkov ${ }^{1}$; Ilya V. Sazhin, $\mathrm{PhD}^{1}$; Aleksandr N. Alimov, PhD, ScD ${ }^{3}$; \\ Leonid V. Safonov, $\mathrm{PhD}^{4 *}$; Sarkis A. Asratyan, $\mathrm{PhD}^{1}$ \\ ${ }^{1}$ Budgetary Institution of Health «Clinical Hospital V.M. Buyanova» \\ ${ }^{2}$ State Budgetary Institution of Healthcare of the City of Moscow «City Clinical Hospital No. 29» \\ ${ }^{3}$ Pirogov Russian National Research Medical University \\ ${ }^{4}$ Federal Scientific Center for Physical Culture \& Sport \\ Moscow, the Russian Federation
}

\begin{abstract}
The article discusses the morphological changes in the mucous membrane of the stomach, duodenum, small intestine and large intestine after gastrostomy performed by the proposed original method of using an implant, in comparison with the classical Witzel gastrostomy and Depage-Janeway gastrostomy using the GIA stapler in laboratory animals (rabbits). Morphological changes were studied on Days 10 and 20 after surgery. It has been shown that gastrostomy causes adaptive-compensatory changes of a various nature, developing along the conveyor principle (along the passage of the food bolus), the morphological picture of which is represented by lymphohistiocytic infiltration and hemocirculatory disorders of a congested origin. The study revealed that the proposed original method of gastrostomy is characterized by a minimal damaging effect on the lower gastrointestinal tract, in comparison with the studied analogues. (International Journal of Biomedicine. 2020;10(3):251-256.)
\end{abstract}

Key Words: gastrostomy $\bullet$ gastrointestinal tract $\bullet$ morphology $\bullet$ polypropylene mesh

\section{Abbreviations}

GC, goblet cells; SI, small intestine; LI, large intestine; LGT, lower gastrointestinal tract

\section{Introduction}

Gastrostomy, in its various modifications, remains the only way to organize enteral nutrition in patients with tumor lesions of the upper gastrointestinal tract. However, this breaks down the conveyor principle of the organization of digestion, which

*Corresponding author: Leonid V. Safonov, PhD. Federal Scientific Center for Physical Culture \& Sport; Moscow, Russia. E-mail: lsaf@mail.ru consists in the sequential effect of enzymes from different parts of the gastrointestinal tract on the food bolus, which ultimately leads to morphofunctional transformations of various parts of the gastrointestinal tract, reducing the efficiency of digestion and becoming a risk factor for the development of a number of diseases. Studies carried out in adult patients present, as a rule, complications of gastrostomy, primarily as a result of technical errors in the performance of the operation, considered in isolation from micro- and macrostructural rearrangements of the lower gastrointestinal tract (LGT) and a complex of metabolic disorders associated with them..$^{(1,2)}$ 
The purpose of this work was to evaluate the morphofunctional changes in the gastrointestinal mucosa in the original method of gastrostomy using a polypropylene mesh, in comparison with the classical Witzel gastrostomy and Depage-Janeway gastrostomy using the GIA stapler.

\section{Materials and Methods}

For the experiment, we selected 18 sexually mature male rabbits ( 3 months old) of the Chinchilla breed, weighing 2500-3400g The animals were divided by the method of pair analogues into 3 groups ( 6 animals each). The work with animals was carried out in accordance with the principles of humanism laid down in the directives of the European Community (86/609/EEC) and the Declaration of Helsinki, in accordance with the "Animal experimentation legislations".

Group 1 rabbits underwent the Witzel's gastrostomy; Group 2 rabbits underwent the Depage-Janeway gastrostomy using the GIA apparatus; Group 3 rabbits underwent the original method of gastrostomy using a polypropylene mesh (Patent RU No. 2691924, Priority date: 06/18/2019, Bulletin No. 17).(3)

The animals were withdrawn from the study on Days 10 and 20 after surgery. The fragments of the membrane of the wall of the gastric fundus, the duodenum, and the initial part of the small intestine (SI) and large intestine (LI) were fixed for at least 2 hours in a $10 \%$ solution of neutral formalin. Further sample processing was carried out by intermediate Blick mixtures. Subsequently, paraffin sections 5-7 $\mu \mathrm{m}$ thick were made, which were stained with H\&E. To identify acidic glycosaminoglycans, which are of particular importance in formation of connective tissue, staining with Alcian blue ( $\mathrm{pH} 2.5$ ) was used..$^{(4)}$

Morphometry was performed using the ImageJ-1.45s. On sections of the gastric mucosa, the following was determined: the number of mucous cells in one fundic gland. the number of goblet cells (GC) of the surface epithelium, the number of of crypt epithelium, lymphocytes in the infiltrate (per $1 \mathrm{~mm}^{2}$ of the stroma), and the height of the mucous membrane glands of the fundus $(\mu \mathrm{m})$. On sections of the mucous membrane of the duodenum, the following was determined: the total number of the cells of the epithelial layer per $1 \mathrm{~mm}$, the number of GC per 100 epithelial cells, the height of the microvilli of the apical plasmatic membrane $(\mu \mathrm{m})$, the height of the villi $(\mu \mathrm{m})$, and the depth of crypts $(\mu \mathrm{m})$. On sections of the mucous membrane of the SI, the following were determined: the height of the villi $(\mu \mathrm{m})$, the depth of crypts $(\mu \mathrm{m})$, the thickness of the brush border of epithelial cells and the number of GC per crypt. On sections of the mucous membrane of the LI, the following were determined: the number of $\mathrm{GC}$ of the surface epithelium, the number of GC of crypt epithelium and lymphocytes in the infiltrate (per $1 \mathrm{~mm}^{2}$ of the stroma).

Statistical analysis was performed using the statistical software «Statistica». (v10.0, StatSoft, USA) and Microsoft Excel 2007. Baseline characteristics were summarized as frequencies and percentages for categorical variables and as mean \pm SEM for continuous variables. The Mann-Whitney (U Test) was used to compare the differences between the two independent groups. A probability value of $P \leq$ was considered statistically significant.

\section{Results}

On Days 10 and 20 after surgery, morphological changes in the wall of the stomach and duodenum in Groups 1 and 2 progressively increased (Fig.1).

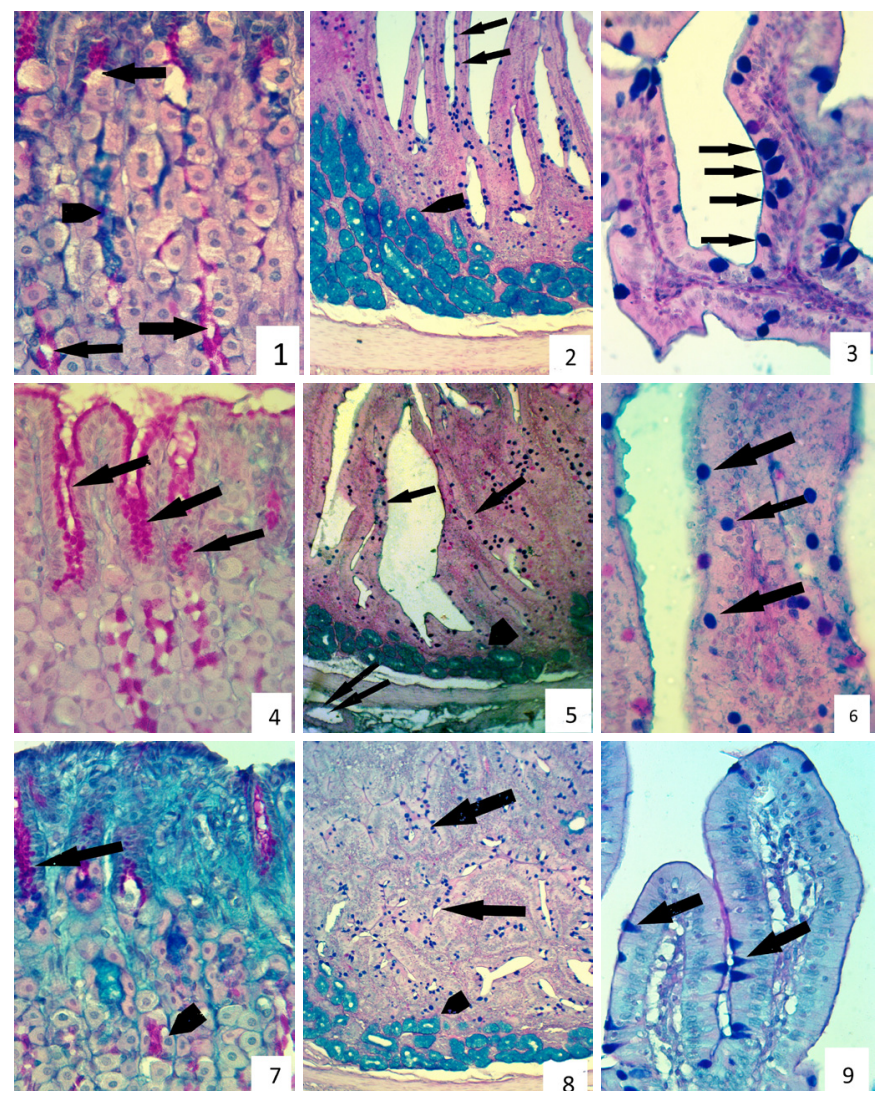

Fig.1. Mucous membrane of the stomach and duodenum. Day 20 after surgery, staining with Alcian blue ( $\mathrm{pH}$ 2.5). Group 1 (1.1, 1.2, 1.3) (Witzel's gastrostomy); Group $2(1.4,1.5,1.6)$ (Depage-Janeway gastrostomy); Group 3 (1.7, 1.8, 1.9) (Original method of gastrostomy).

1.1. Lens 40. The apical part of the glands of the gastric mucosa. Neutral polysaccharides in the cytoplasm of gastric glandulocytes.

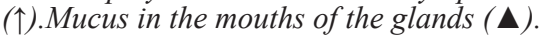

1.2 Lens 10. The wall of the duodenum. An increase in the number of goblet cells $(\uparrow)$ in the sparse villi of the duodenum. The volume of the end sections of the duodenal glands is significantly increased $(\mathbf{\Delta})$.

1.3 Lens 40. A section of the villus of the duodenum. Numerous, large, dense mucin-filled $G C(\uparrow)$. Inactive, narrowed vessels of the microvilli of the duodenum $(\mathbf{\Delta})$.

1.4 Lens 40. The apical part of the glands of the gastric mucosa. Accumulation of neutral polysaccharides in a large number of gastric glandulocytes $(\uparrow)$.

1.5 Lens 10. The wall of the duodenum. Sparsely located villi with a large number of $G C(\uparrow)$. Empty vein lumen ( $\uparrow)$. The volume of the end sections of the duodenal glands is reduced compared to Group 1 ( $\mathbf{\Delta})$.

1.6 Lens 40. A section of the villus of the duodenum. Numerous, dense mucin-filled $G C(\uparrow)$.The size of the cells is slightly reduced compared to Group 1.

1.7 Lens 40. The apical part of the glands of the gastric mucosa. Decreased synthesis of neutral polysaccharides in the cytoplasm of gastric glandulocytes ( $\uparrow$ ) and an increase in the synthesis of acidic glycosaminoglycans $(\mathbf{\Delta})$.

1.8 Lens 10. The wall of the duodenum. Densely arranged complexshaped villi ( $\uparrow)$.The volume of the end sections of the duodenal glands is reduced compared to Group 1 ( $\mathbf{\Delta})$.

1.9 Lens 40. A section of the villus of the duodenum. Few, small GC ( $\uparrow)$. 
In Group 1, neutral polysaccharides in the glandular cells of the fundus of the stomach were detected, first in the mouths and subsequently in the body of the stomach's glands. On Day 20 after surgery, an increase in acidic glycoproteins (mucin) was also noted in the same places. In the duodenum, the villi became shorter and less numerous, the space between them was expanded, and a significant number of large rounded $\mathrm{GC}$ with cytoplasm filled with intensely staining alcianophilic inclusions were found in their epithelium. The brush border of the enterocytes was shortened. The vessels of the microvilli had a collapsed lumen free from blood cells (Fig. 1.1, 1.2, 1.3). The cells of the terminal sections of the duodenal glands were intensely stained and the glands became numerous, which caused the submucosa to become significantly thickened.

In Group 2, the changes in the morphological structure of the mucous membrane of the stomach and duodenum were very similar to the changes in Group 1 (Fig. 1.4, 1.5, 1.6). However, in the stomach, the above-described changes were less pronounced, and only captured the in mouths of the glands and in the duodenum, the conglomerates of the terminal sections of the duodenal glands were not so massive.

In Group 3, the changes were minimal (Fig. 1.7, 1.8, 1.9). In the stomach, they covered only the mouths of the glands; in the duodenum, densely located high villi with small $\mathrm{GC}$ remained. However, as in other groups, the villous vessels were empty.

The dynamics of morphometric changes in Groups 1 and 2 progressively increased over time, most pronounced in Group 1, which consisted in a significant increase in the average number of mucous cells and a decrease in the average height of the glands in the fundus of the stomach. Changes in the above indicators in Group 3 were minimal (Table 1).

\section{Table 1.}

The morphological parameters of the mucous membrane of the stomach

\begin{tabular}{|l|c|c|c|c|}
\hline \multicolumn{1}{|c|}{ Parameter } & $\begin{array}{c}\text { Day after } \\
\text { surgery }\end{array}$ & Group 1 & Group 2 & Group 3 \\
\hline \multirow{2}{*}{$\begin{array}{l}\text { Number of mucous } \\
\text { cells per one fundic } \\
\text { gland }\end{array}$} & 10 & $17.1 \pm 0.4$ & $16.8 \pm 0.4$ & $14.2 \pm 0.3^{*, * *}$ \\
\cline { 2 - 5 } & 20 & $18 \pm 0.4$ & $18 \pm 0.4$ & $15 \pm 0.2^{*, * *}$ \\
\hline $\begin{array}{l}\text { Height of the } \\
\text { mucous membrane } \\
\text { glands of the } \\
\text { fundus, } \mu \mathrm{m}\end{array}$ & 10 & $575.8 \pm 5.5$ & $582.1 \pm 5.8$ & $591.9 \pm 5.2^{*, * *}$ \\
\cline { 2 - 5 } & 20 & $453 \pm 4$ & $468.7 \pm 4.6$ & $587.5 \pm 6.5^{*, * *}$ \\
\hline
\end{tabular}

$* P<0.05$ between Group 1 and Group 3; **P<0.05 between Group 2 and Group 3

The revealed heterochrony in the dynamics of the studied parameters should be noted: The indices of the density of $\mathrm{GC}$ were the first to change, while the other indices showed reliable dynamics only on Day 20 after surgery. Morphological changes in the wall of the small and large intestines in all studied groups on Day 10 after surgery had a minimal severity; however, on Day 20, they progressively increased in Groups 1 and 2.
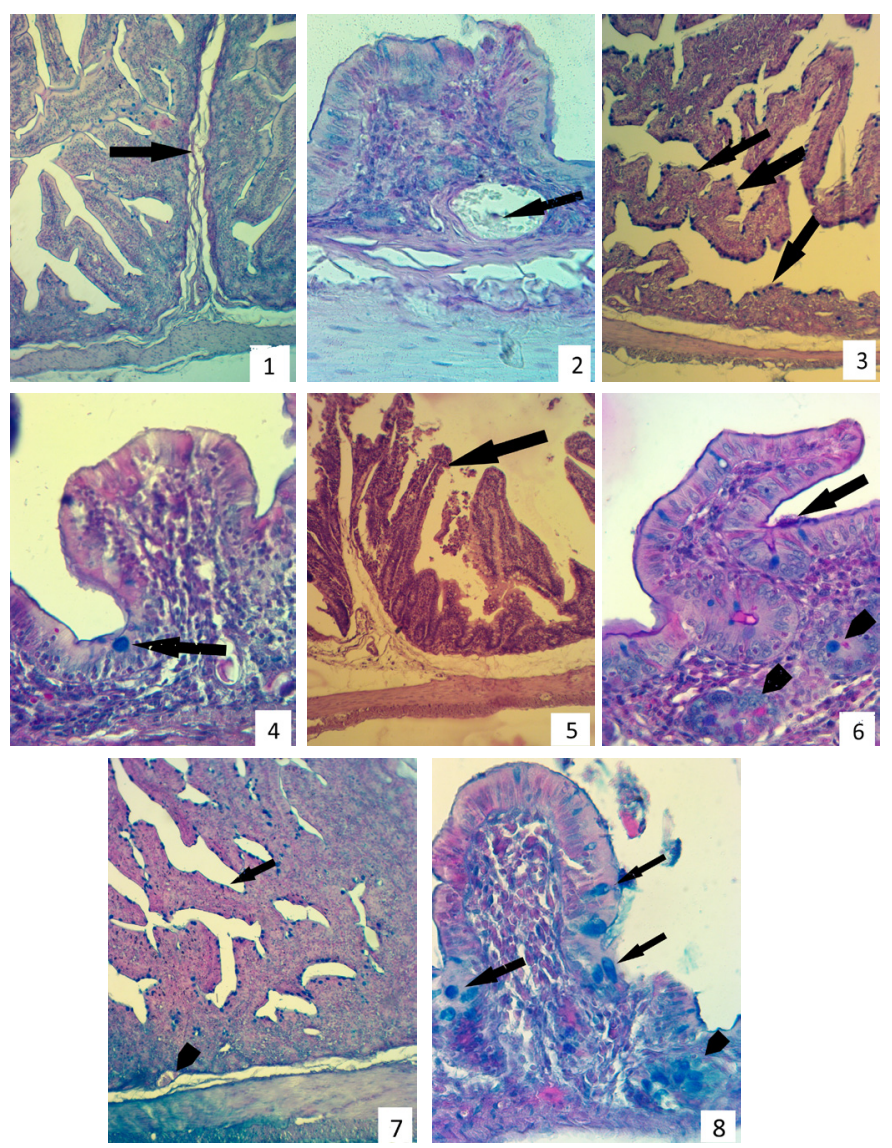

Fig. 2. Mucous membrane of the SI and LI, staining with Alcian blue ( $p H$ 2.5). Group 1 (2.1, 2.2, 2.5, 2.6) (Witzel's gastrostomy); Group 3 (2.3, 2.4, 2.7, 2.8) (Original method of gastrostomy). 2.1, 2.2, 2.3, 2.4 - Day 10 after surgery; 2.5, 2.6, 2.7, 2.8 - Day 20 after surgery.

2.1 Lens 10. Small intestine. The villus of the small intestine with central collapsed vessels $(\uparrow)$.

2.2 Lens 40. Large intestine with numerous mucus-secreting GC. Intestinal villi; sludge of erythrocytes in the lumen of the vein ( $\uparrow)$.

2.3. Lens 10. Small intestine. Numerous villi of the small intestine with complex relief $(\uparrow)$.

2.4. Lens 40. Colon. Intestinal villus. Sparse, compact, inactive goblet cells $(\uparrow)$.

2.5. Lens 10. Small intestine. A short villus of the small intestine with few secondary villi $(\uparrow)$ and empty vessels.

2.6. Lens 40. Large intestine. Intestinal villus. Numerous GC in a degranulated state $(\uparrow)$. Lymphoid nodules $(\mathbf{\Delta})$.

2.7 Lens 10. Small intestine. Long numerous villi of the small intestine with a complex relief $(\uparrow)$. Aggregation of erythrocytes in a vein $(\mathbf{\Delta})$.

2.8 Lens 40. Large intestine. Intestinal villus. GC, partly compact, partly degranulated $(\uparrow)$.Lymphoid nodule $(\mathbf{\Delta})$.

On Day 10 after surgery, a desolation of the venous vessels and spasm of arterioles, as well as an increase in the number of GC, were observed in the villi of the SI. The epithelium of the LI was characterized by a slight increase in the number of GC (Fig. 2.1, 2.2).

In Group 2, the morphological picture was largely similar to the morphological picture in Group 1. In Group 3, minimal changes were revealed (Table 2). 
Table 2.

The morphological parameters of the mucous membrane of the duodenum

\begin{tabular}{|l|c|c|c|c|}
\hline \multicolumn{1}{|c|}{ Parameter } & $\begin{array}{c}\text { Day after } \\
\text { surgery }\end{array}$ & Group 1 & Group 2 & Group 3 \\
\hline $\begin{array}{l}\text { Total number of the } \\
\text { cells of the epithelial } \\
\text { layer per 1mm }\end{array}$ & 10 & $103 \pm 7$ & $110 \pm 7$ & $112 \pm 9$ \\
\cline { 2 - 5 } & 20 & $84 \pm 6$ & $87 \pm 8$ & $102 \pm 8^{*, * *}$ \\
\hline $\begin{array}{l}\text { The number of GC } \\
\text { per 100 epithelial } \\
\text { cells }\end{array}$ & 10 & $20.2 \pm 1.7$ & $15.9 \pm 1.2$ & $14.1 \pm 1.4^{* * * *}$ \\
\cline { 2 - 5 } & 20 & $22.8 \pm 1.9$ & $18.6 \pm 1.9$ & $16.2 \pm 1.4^{* * * *}$ \\
\hline $\begin{array}{l}\text { The height of the } \\
\text { microvilli of the } \\
\text { apical plasmatic } \\
\text { membrane }(\mu \mathrm{m})\end{array}$ & 10 & $2.3 \pm 0.2$ & $2.4 \pm 0.2$ & $2.5 \pm 0.2$ \\
\cline { 2 - 5 } & 20 & $2 \pm 0.1$ & $2 \pm 0.1$ & $2.4 \pm 0.2^{*, * *}$ \\
\hline $\begin{array}{l}\text { The height of the } \\
\text { villi }(\mu \mathrm{m})\end{array}$ & 10 & $440.5 \pm 4.1$ & $440.7 \pm 4.2$ & $445.2 \pm 3.4$ \\
\cline { 2 - 5 } & 20 & $388.7 \pm 3.7$ & $417.9 \pm 2.9$ & $432.2 \pm 2.8^{*, * *}$ \\
\hline \multirow{2}{*}{$\begin{array}{l}\text { The depth of crypts } \\
(\mu \mathrm{m})\end{array}$} & 10 & $205 \pm 2.4$ & $202.8 \pm 1.9$ & $209 \pm 1.9^{* * *}$ \\
\cline { 2 - 5 } & 20 & $172 \pm 1.9$ & $178.2 \pm 1.9$ & $186.9 \pm 1.8^{*, * *}$ \\
\hline
\end{tabular}

${ }^{*} P<0.05$ between Group 1 and Group 3; ${ }^{*} P<0.05$ between Group 2 and Group 3

A distinctive feature from other groups was the presence of rare and compact inactive GC in the LI in Group 3 (Fig. $2.3,2.4)$.

On Day 20 after surgery, in Groups 1 and 2, a progressive increase in changes in the SI was revealed. The villi of the SI in both groups shortened over time, their vessels became empty, and the number of GC in crypts increased. The submucosa was dilated and looked edematous. In the vessels of the microcirculatory bed, signs of venous hyperemia were noted: sludge of erythrocytes in the veins and venules, blood plasma separation. The number of lymphoid elements increased, most pronounced in the large intestine. The lymphoid nodules increased in size, and the bright germinal center was clearly visualized (Fig. 2.5, 2.6). In the loose, fibrous connective tissue, the density of areas of lymphohistiocytic infiltration increased, and single lymphocytes were more common.

In Group 3, a crypt-villus system was characterized by the complex branched relief and sufficient crypt depth with a small number of GC. At the same time, slight disturbances of microcirculation were noted in the form of venous stasis, parietal aggregation of erythrocytes with the formation of "coin columns." In the large intestine, the changes were close to the morphological picture of Groups 1 and 2, but they were less pronounced (Fig. 2.7, 2.8). The lymphoid nodules were partially oval and smaller in size, and lymphoid nodules without a pronounced, bright germinal center were also rare. Disturbances of microcirculation in the form of pronounced parietal aggregation of erythrocytes with the formation of large conglomerates ("coin columns") in the vessels of the LI are shown in Figure 2 (2.7).

The results of the morphometry of the height of the villi and crypts in the SI showed a decrease in these parameters in Groups 1 and 2 from Day 10 up to Day 20 after surgery.
At the same time, similar indicators in Group 3 did not change significantly. The average number of GC per crypt progressively increased throughout the study in all groups. The thickness of the brush border significantly decreased only on Day 20 after surgery, lagging behind other parameters. The intensity of the decrease in morphometric parameters in Groups 1 and 2 remained at approximately the same level, while in Group 3 it was significantly lower (Table 3 ).

Table 3.

The morphological parameters of the mucous membrane of the small intestine

\begin{tabular}{|l|c|c|c|c|}
\hline \multirow{2}{*}{ Parameter } & $\begin{array}{c}\text { Day after } \\
\text { surgery }\end{array}$ & Group 1 & Group 2 & Group 3 \\
\hline $\begin{array}{l}\text { The height of } \\
\text { the villi }(\mu \mathrm{m})\end{array}$ & 10 & $340.4 \pm 3.4$ & $341.4 \pm 3.6$ & $357.9 \pm 3.7^{*, * *}$ \\
\cline { 2 - 5 } & 20 & $280.4 \pm 3$ & $301.3 \pm 2.8$ & $321 \pm 3.2^{*, * *}$ \\
\hline $\begin{array}{l}\text { The depth of } \\
\text { crypts }(\mu \mathrm{m})\end{array}$ & 10 & $228.5 \pm 2.1$ & $233.9 \pm 2.1$ & $232.1 \pm 2.4^{*}$ \\
\cline { 2 - 5 } & 20 & $205.3 \pm 2.1$ & $210.6 \pm 2.1$ & $212.5 \pm 1.9^{*}$ \\
\hline $\begin{array}{l}\text { The thickness } \\
\text { of the brush } \\
\text { border of } \\
\text { epithelial cells }\end{array}$ & 10 & $1.85 \pm 0.19$ & $1.84 \pm 0.19$ & $1.89 \pm 0.14$ \\
\cline { 2 - 5 } & 20 & $1.74 \pm 0.18$ & $1.76 \pm 0.15$ & $1.87 \pm 0.09^{*, * *}$ \\
\hline $\begin{array}{l}\text { The number of } \\
\text { GC per crypt }\end{array}$ & 10 & $20.2 \pm 0.2$ & $19.8 \pm 0.2$ & $18.8 \pm 0.2^{*, * *}$ \\
\cline { 2 - 5 } & 20 & $22.8 \pm 0.3$ & $21.4 \pm 0.2$ & $19.2 \pm 0.2^{*, * *}$ \\
\hline
\end{tabular}

$* P<0.05$ between Group 1 and Group 3; **P<0.05 between Group 2 and Group 3

The dynamics of morphometric changes in the mucous membrane of the LI was the least pronounced, in comparison with other parts of the intestine. There were practically no statistically significant differences between the studied parameters on Day 10 after the start of the study. On Days 10 and 20 after surgery, significant differences were found between the indicators in Groups 3 and 1: an increase in the number of GC and cells of lymphohistiocytic infiltrate in Group 1, compared with similar indicators in Group 3 (Table 4).

\section{Table 4.}

The morphological parameters of the mucous membrane of the large intestine

\begin{tabular}{|l|c|c|c|c|}
\hline \multicolumn{1}{|c|}{ Parameter } & $\begin{array}{c}\text { Day after } \\
\text { surgery }\end{array}$ & Group 1 & Group 2 & Group 3 \\
\hline $\begin{array}{l}\text { The number of } \\
\text { GC of the surface } \\
\text { epithelium }\end{array}$ & 10 & $12.4 \pm 0.1$ & $12.5 \pm 0.2$ & $12.4 \pm 0.2$ \\
\cline { 2 - 5 } & 20 & $15.1 \pm 0.5$ & $12.4 \pm 0.2$ & $12.5 \pm 0.2^{*}$ \\
\hline $\begin{array}{l}\text { The number of GC } \\
\text { of crypt epithelium }\end{array}$ & 10 & $38 \pm 0.6$ & $38.2 \pm 0.7$ & $38.4 \pm 0.9$ \\
\cline { 2 - 5 } & 20 & $39.3 \pm 0.7$ & $39 \pm 0.8$ & $38.9 \pm 0.6$ \\
\hline $\begin{array}{l}\text { Lymphocytes in the } \\
\text { infiltrate (per 1 mm } \\
\text { of the stroma) }\end{array}$ & 10 & $2391 \pm 164$ & $2397 \pm 157$ & $2378 \pm 146$ \\
\cline { 2 - 5 } & 20 & $2885 \pm 205$ & $2638 \pm 200$ & $2465 \pm 212^{*, * *}$ \\
\hline
\end{tabular}

$* P<0.05$ between Group 1 and Group 3; **P<0.05 between Group 2 and Group 3 
The increase we observed in the synthesis of neutral polysaccharides in the upper sections of the fundic glands of the stomach was the most intense in Groups 1 and 2, as a rule, accompanied by a drop in the rate of mucin synthesis by epithelial cells of the deep sections-gastric pits and pyloric glands - which characterizes a decrease in the barrier properties of the stomach. ${ }^{(5)}$ It is known that acidic mucins normally play a protective role. In this regard, the appearance of acidic glycosaminoglycans in epithelial cells in Group 1 is considered as a compensatory response to chronic damage, since acidic glycosaminoglycans have better protective properties against destruction by bacterial enzymes. ${ }^{(6)}$

The morphofunctional features of the mucous membrane of the small intestine are determined by the presence of three types of specific formations: intestinal villi, Lieberkühn crypts and organized lymphoid nodules (single and group). ${ }^{(7)}$ This allows us to identify three vectors of changes after performing various variants of gastrostomy, recorded in our study. A revealed decrease in the height of the villi and in the height of the brush border in our study can lead to a decrease in parietal digestion and absorption of monomers. ${ }^{(8)}$ This is also evidenced by the desolation of the villous vessels, the morphometric characteristics of which are considered the most significant signs reflecting the dynamics of hemocirculatory disorders in the intestine..$^{(9)}$

Since intestinal stem cells are located at the base of intestinal crypts and are responsible for renewing the intestinal epithelial lining to maintain cellular homeostasis, it can be concluded that a decrease in crypt depth is a morphological sign of a decrease in the regenerative activity of the epithelium of the small intestine.

An increase in the number of GC and layer formation in Groups 1 and 2 over time contributes to the growth of bacterial and toxic aggression, since the changes in the morphological properties of epithelial villi observed in our study are similar to those described in the work of Ruan et al. ${ }^{(10)}$ The results obtained by Nan et al. ${ }^{(11)}$ also testify to a similar negative effect of endotoxins on the morphological characteristics of villi. It was found that modeling of toxic effects by incubation of the jejunum of rats with E. coli M17 cells stimulates abundant mucus secretion. In this regard, the increase in the number of GC revealed in our study and, accordingly, the mucus produced by them, can be regarded as a protective mechanism against an increase in the toxic effect into the small intestine. ${ }^{(12)}$

This is also evidenced by neutrophilic infiltration of the intestinal mucosa, which was also identified in our study and which is a hallmark of inflammation of the gastrointestinal tract with significant adverse effects on the body ${ }^{(13)}$ Normally, the content of neutrophils in the intestinal mucosa is insignificant, while during inflammation it increases sharply; cells migrate across the epithelial barrier and appear on the surface of the villi. ${ }^{(14)}$

The activity of the lymphoid nodules of the large intestine revealed in our study, as well as an increase in the density of the lymphohistiocytic infiltrate of the submucosa, can be interpreted as an increase in the microbial and toxic load from the overlying parts of the intestine, since the lymphoid tissue in the walls of the hollow organs of the digestive system is the main protective immunological barrier of the body. ${ }^{(15)}$

The absence of statistically significant differences when comparing the morphometric parameters of the large intestine 10 days after surgery is probably because the large intestine is less susceptible to ischemic and toxic tissue damage than the small intestine. ${ }^{(16)}$

\section{Conclusions:}

The adaptive-compensatory rearrangements in the mucous membrane of the stomach and the lower gastrointestinal tract that were revealed after 10 days of the experiment progress in all the studied groups by the end of the study. The maximum changes were found in the stomach. As the food bolus passes towards the lower gastrointestinal tract, the revealed changes are gradually leveled.

The morphological picture of adaptive-compensatory rearrangements includes an increase in morphological equivalents of protective factors and morphological signs of a decrease in parietal digestion processes developing against the background of activation of the lymphocystiocytic system. This is accompanied by impaired microcirculation of the congestive venous type.

The choice of the gastrostomy method has a significant impact on the lower gastrointestinal tract, where the adaptivecompensatory changes develop along the passage of the food bolus.

The original gastrostomy method we developed is characterized by a minimal damaging effect on the lower gastrointestinal tract, in comparison with the studied analogues.

\section{Competing Interests} interests.

The authors declare that they have no competing

\section{References}

1. Kostyuchenko LN, Kostyuchenko MV, Smirnova OA. [Metabolic complications of parenteral-enteral nutrition]. Experimental \& Clinical Gastroenterology]. 2015;120(8):5155. [Article in Russian].

2. Leiderman IN, Girsh AO, Smirnov MV, Sytov AV. [Recommendations for nutritional support in palliative medicine]. Palliative Medicine and Rehabilitation. 2015;(3):38-43. [Article in Russian].

3. Vaganov AG, Tsulaya AS, Shurygin SN. Patent RU No. 2691924 of 06/18/2019; Bulletin No. 17. [In Russian].

4. Davenport M, Spitz L, Coran A. Operative Pediatric Surgery, Seventh Edition. London; 2013.

5. Mogil'naya VL. [Comparative characteristics of the gastric mucosa in the early stages after corrective operations bulletin of higher educational institutions]. North Caucasus Region. Technical Sciences. 2006;(8):126-127. [Article in Russian].

6. Deplancke B, Gaskins HR. Microbial modulation of innate defense: goblet cells and the intestinal mucus layer. Am J Clin Nutr. 2001;73(6):1131S-1141S. doi:10.1093/ajen/73.6.1131S

7. Voronik YuN, Matsyuk YaR. [Age dynamics of structural 
and cytochemical parameters of the jejunum of rats]. Journal of the Grodno State Medical University. 2018;16(3):272-278. [Article in Russian].

8. Stieler Stewart A, Freund JM, Blikslager AT, Gonzalez LM. Intestinal Stem Cell Isolation and Culture in a Porcine Model of Segmental Small Intestinal Ischemia. J Vis Exp. 2018;(135):57647. Published 2018 May 18. doi:10.3791/57647 9. Elyasin PA, Zalavina SV, Mashak AN, Nadeev AP, Aydagulova SV. [Small intestine morphology of adolescents rats in chronic intoxication with cadmium sulfate].Ulyanovsk Medico-Biological Journal. 2018;(3):151-156. [Article in Russian].

10. Ruan Z, Liu S, Zhou Y, Mi S, Liu G, Wu H, etal. Chlorogenic acid decreases intestinal permeability and increases expression of intestinal tight junction proteins in weaned rats challenged with LPS. PLoS One. 2014;9(6):e97815. Published 2014 Jun 2. doi:10.1371/journal.pone.0097815

11. Li N, Russell WM, Douglas-escobar M, Hauser N, Lopez M, Neu J. Live and heat-killed Lactobacillus rhamnosus GG: effects on proinflammatory and anti-inflammatory cytokines/ chemokines in gastrostomy-fed infant rats. Pediatr Res. 2009;66(2):203-207. doi:10.1203/PDR.0b013e3181aabd4f
12. Rybalchenko OV, Orlova OG, Korol'kova ED, Fonturenko $\mathrm{AYu}$, et al. [Histological studies of the mucous membrane of the rat small intestine exposed to endotoxin and probiotic bacteria]. Gastroenterology of St. Petersburg. 2018;(2):32-37. [Article in Russian].

13. Sullivan DP, Bui T, Muller WA, Butin-Israeli V, Sumagin $R$. In vivo imaging reveals unique neutrophil transendothelial migration patterns in inflamed intestines. Mucosal Immunol. 2018;11(6):1571-1581. doi:10.1038/s41385-018-0069-5

14. Zamolodchikova TS, Tolpygo SM, Svirshchevskaya EV. [Cadherins and cathepsin $\mathrm{G}$ in the regulation of homeostasis and defense reactions in the intestinal epithelium]. Experimental and Clinical Gastroenterology. 2018;154(6):7477. [Article in Russian].

15. Treuting PM, Dintzis SM, Frevert CW, et al. Comparative anatomy and histology: a mouse and human atlas. Amsterdam: Elsevier/Academic Press; 2012.

16. Hundscheid IH, Grootjans J, Lenaerts K, Schellekens DH, Derikx JP, Boonen BT, et al. The Human Colon Is More Resistant to Ischemia-reperfusion-induced Tissue Damage than the Small Intestine: An Observational Study. Ann Surg. 2015;262(2):304-311. doi:10.1097/SLA.0000000000001131 